\title{
Adverse events and the relation with quality of life in adults with intellectual disability and challenging behaviour using psychotropic drugs
}

\author{
Arlette Scheifes $^{\text {a,b }}$, Sanne Walraven ${ }^{\text {a }}$, Joost Jan Stolker ${ }^{\text {a,c }}$, Henk L.I. Nijman ${ }^{\text {b,d }}$, \\ Toine C.G. Egberts ${ }^{\mathrm{a}, \mathrm{e}}$, Eibert R. Heerdink ${ }^{\mathrm{a}, \mathrm{b}, \mathrm{e}, *}$ \\ ${ }^{a}$ Department of Pharmacoepidemiology \& Clinical Pharmacology, Utrecht Institute for Pharmaceutical Sciences, PO Box 80082, 3508 TB \\ Utrecht, The Netherlands \\ ${ }^{\mathrm{b}}$ Altrecht Aventurijn, Vuurvlinder 4, 3734 AB, Den Dolder, The Netherlands \\ ${ }^{\mathrm{C}}$ Licht-Zorg, psychiatric care, De Hoopkade 22, 3604 DZ Maarssen, The Netherlands \\ ${ }^{\mathrm{d}}$ Behavioural Science Institute (BSI), Faculty of Social Sciences, Radboud University Nijmegen, PO Box 9104, 6500 HE Nijmegen, The \\ Netherlands \\ ${ }^{\mathrm{e}}$ Department of Clinical Pharmacy, University Medical Centre Utrecht, PO Box 85500, 3508 GA Utrecht, The Netherlands
}

\section{A R T I C L E I N F O}

\section{Article history:}

Received 13 April 2015

Received in revised form 11 November 2015

Accepted 19 November 2015

Available online 29 November 2015

\section{Keywords:}

Intellectual disability

Challenging behaviour

Pharmacotherapy

Quality of life

Adverse events

Safety

\begin{abstract}
A B S T R A C T
Background: Psychotropic drugs are prescribed to approximately $30-40 \%$ of adults with intellectual disability (ID) and challenging behaviour, despite the limited evidence of effectiveness and the potential of adverse events.

Aims: To assess the prevalence of adverse events in association with psychotropic drug use in adults with ID and challenging behaviour and to examine the relation of these adverse events with the person's quality of life.

Method: The presence of adverse events was measured with a questionnaire that had to be filled in by the physicians of the participants. Movement disorders were measured separately with a standardised protocol. The strength of the association between adverse events and Intellectual Disability Quality of Life-16 (IDQOL-16), and daily functioning was investigated using linear regression analyses, taking into account the severity of disease (CGI-S) as potential confounder.

Results: Virtually all of 103 adults with ID and challenging behaviour had at least one adverse event (84.4\%) and almost half had $\geq 3$ adverse events (45.6\%) across different subclasses. Using psychotropic drugs increased the prevalence of adverse events significantly. Respectively $13 \%$ of the patients without psychotropic drugs and $61 \%$ of the patients with $\geq 2$ psychotropic drugs had $\geq 3$ adverse events. Having adverse events had a significantly negative influence on the quality of life.

Conclusions: A large majority of all patients had at least one adverse event associated with psychotropic drug use. More attention is needed for these adverse events and their negative influence on the quality of life of these patients, taking into account the lack of evidence of effectiveness of psychotropic drugs for challenging behaviour.
\end{abstract}

(c) 2015 Published by Elsevier Ltd.

\footnotetext{
* Corresponding author at: Department of Pharmacoepidemiology \& Clinical Pharmacology, Utrecht Institute for Pharmaceutical Sciences, David de Wied building, PO Box 80082, 3508 TB Utrecht, The Netherlands, Tel.: +31 30 2537324; fax: +31 302539166 .

E-mail addresses: a.scheifes@uu.nl (A. Scheifes), s.walraven@students.uu.nl (S. Walraven), joostjan.stolker@gmail.com (J.J. Stolker), h.nijman@altrecht.nl (Henk L.I. Nijman), a.c.g.egberts@uu.nl (Toine C.G. Egberts), e.r.heerdink@uu.nl (E.R. Heerdink).
} 


\section{Introduction}

The prevalence of challenging behaviour in adults with intellectual disability (ID) is high: estimates vary from $20 \%$ to over 50\%, depending on the setting, definition and measurement method (Cooper, Smiley, Morrison, Williamson, \& Allan, 2007; Cooper et al., 2009; Crocker et al., 2006; Deb, Thomas, \& Bright, 2001; Singh, Ellis, \& Wechsler, 1997). In these people psychotropic drugs, especially antipsychotics, are frequently (30-40\%) used to treat the challenging behaviour even though there is a lack of evidence of effectiveness and a considerable risk of adverse drug reactions (Brylewski \& Duggan, 1999; de Kuijper et al., 2010; Deb \& Unwin, 2007; Holden \& Gitlesen, 2004; Matson \& Mahan, 2010; Matson \& Neal, 2009; Scheifes, Stolker, Egberts, Nijman, \& Heerdink, 2011; Tsiouris, 2010; Tsiouris, Kim, Brown, Pettinger, \& Cohen, 2013). Most adults with ID treated with antipsychotics use them for many years, sometimes even decades (de Kuijper et al., 2013).

Frequently occurring adverse events of psychotropic drug use are, amongst others, psychological symptoms (e.g., sedation, inner unrest), neurological symptoms (e.g., epileptic seizures, dyskinesia), weight changes, sexual symptoms (e.g., diminished sexual desire, erectile dysfunction) and psychological or physical dependence (Advokat, Mayville, \& Matson, 2000; Deb \& Unwin, 2007; Friedlander, Lazar, \& Klancnik, 2001; Frighi et al., 2011; Mahan et al., 2010; McKee, Bodfish, Mahorney, Heeth, \& Ball, 2005; Roke, Buitelaar, Boot, Tenback, \& Van Harten, 2012). These adverse events can be more difficult to detect in adults with ID than those without ID, because impaired communication of the adult with ID hampers the recognition and interpretation of signs and symptoms (Dosen \& Day, 2001). Furthermore the adverse event may overlap with the appearance of the psychopathology; for example irritability and agitation may seem a psychiatric or behavioural symptom instead of an adverse event (Charlot et al., 2011; Valdovinos, Caruso, Roberts, Kim, \& Kennedy, 2005).

Although quality of life is an important aspect of treatment outcome, measurements of quality of life are rarely included in pharmacological intervention studies in adults with ID (Bertelli et al., 2013; Hemmings, Deb, Chaplin, Hardy, \& Mukherjee, 2013; Zarcone, Napolitano, \& Valdovinos, 2008). Studies on the effect of psychotropic drugs report adverse events as secondary outcomes (Aman et al., 2002; Gagiano, Read, Thorpe, Eerdekens, \& Van Hove, 2005; Snyder et al., 2002; Tyrer et al., 2008). A small percentage of published studies systematically address adverse events and risk factors thereof (de Kuijper et al., 2013; Fodstad et al., 2010; Frighi et al., 2011; Mahan et al., 2010). There are no studies on the consequences of adverse events on the quality of life.

The aim of this study was to assess the prevalence of adverse events in association with psychotropic drug use in adults with ID and challenging behaviour and to examine the relation of these adverse events with the person's quality of life.

\section{Methods}

\subsection{Setting and study design}

A cross sectional study was conducted in three Dutch inpatient treatment facilities (Wier-Altrecht Aventurijn, Ipse de Bruggen, Hoeve Boschoord-Trajectum) for adults with mild to borderline ID and severe challenging behaviour. Adults with ID are referred to these institutions if treatment in general mental health institutions and/or specialised units of residential settings leads to unsatisfactory results regarding their challenging behaviour. The medical ethical committee of the University Medical Centre Utrecht approved the study. The research period was from August 2009 until October 2011.

\subsection{Participants}

All admitted persons to the participating centres were eligible if they were able to give informed consent to participate in this study. Persons admitted to the centres before the start of the study period as well as persons newly admitted during the study period were included in the current study (and followed up during their admission, or the end of data collection). Participants were informed about the study and its goals, and gave permission through an informed consent procedure. Because of the nature of the treatment facility, all participants exhibited severe challenging behaviour before admission. To be able to compare groups, both people with and without psychotropic medication were included.

Baseline characteristics data were collected from the standardised basic registration lists from the three participating centres. These lists were filled in by the professional staff and contained demographic information (e.g., age, gender and ethnicity) and information on hospitalisation (e.g., duration of stay at the day of measurement and codes of DSM-IV disorders or descriptive diagnoses). Diagnoses were coded according to DSM-IV; if these were not available the descriptive diagnosis was used. These diagnoses were grouped into the following main disorders: psychotic disorders, pervasive developmental disorders, Attention-Deficit/Hyperactive Disorder (ADHD) and conduct disorders, mood disorders, anxiety disorders, alcohol/drug dependence or abuse, personality disorders, sexual disorders and other diagnoses. The categorisation was performed by the authors S.W. and A.S.

Level of intellectual functioning was measured through different standard intelligence scales (e.g., WAIS-III, GIT-2 and WISC-R) and if the IQ was not available, the DSM-IV diagnosis was used (American Psychiatric Association, 2000). The level of intellectual functioning was categorised in the following levels: mild ID (IQ 50-70), borderline intellectual functioning (IQ 71-84) and unspecified. 


\subsection{Assessment of adverse events}

The presence of adverse events was measured by the physicians, both psychiatrists and specialised ID physicians, working at the participating institutions using a questionnaire based on the symptoms mentioned in the Udvalg for Kliniske Undersogelser (UKU) side effects rating scale (Lingjaerde, Ahlfors, Bech, Dencker, \& Elgen, 1987). The physicians were asked to fill in this questionnaire without seeing the patient directly, but with their last contact with the patient in mind. The time since their last contact was noted as well. The physicians had to tick boxes if adverse events were present/absent/unknown. Different categories of adverse events were: sleeping problems and fatigue, psychological symptoms, neurological symptoms, anticholinergic symptoms, gastro-intestinal symptoms, urogenital symptoms, cardiovascular symptoms, weight changes, sexual symptoms, headache symptoms and dependence symptoms (see Table 1).

Neurological symptoms related to movement disorders were omitted from the questionnaire because at approximately the same time of filling in the questionnaires by the physicians a trained physiotherapist measured the movement disorders using a standardised protocol (van Harten, Matroos, Hoek, \& Kahn, 1996). This protocol consisted of the Abnormal Involuntary Movement Scale (AIMS) to measure dyskinesia (Guy, 1976a), the Barnes Akathisia Rating Scale (BARS) to measure akathisia (Barnes, 1989), the motor examination part of the Unified Parkinson Disease Rating Scale (UPDRS) to measure parkinsonism (Martínez-Martín et al., 1994) and one separate item for dystonia. Neurological symptoms were considered present if at least one of these movement disorders was present or epileptic seizure or paraesthesia. Sedation was also added as a separate question to the questionnaire for the physician to measure the degree of sedation. This scale ranged from 1 to 5 , where 1 means no sedation and 5 the highest degree of sedation.

Table 1

Adverse events in categories.

\begin{tabular}{|c|c|}
\hline Category & Adverse events \\
\hline Sleeping problems and fatigue & $\begin{array}{l}\text { Asthenia, fatigue, dullness } \\
\text { Somnolence, sedation } \\
\text { Sleeping longer } \\
\text { Sleeping shorter } \\
\text { Increased dreaming }\end{array}$ \\
\hline Psychological symptoms & $\begin{array}{l}\text { Concentration problems } \\
\text { Memory problems } \\
\text { Depressive symptomatology } \\
\text { Tenseness/internal unrest } \\
\text { Emotional indifference }\end{array}$ \\
\hline Neurological symptoms & $\begin{array}{l}\text { Epileptic seizures } \\
\text { Paraesthesia } \\
\text { Movement disorders }\end{array}$ \\
\hline Anticholinergic symptoms & $\begin{array}{l}\text { Accommodation disorders } \\
\text { Salivation } \\
\text { Dry mouth } \\
\text { Increased sweating }\end{array}$ \\
\hline Gastro-intestinal symptoms & $\begin{array}{l}\text { Nausea/vomiting } \\
\text { Diarrhoea } \\
\text { Constipation }\end{array}$ \\
\hline Urogenital symptoms & $\begin{array}{l}\text { Problems with micturition } \\
\text { Polyuria/polydipsia }\end{array}$ \\
\hline Cardiovascular symptoms & $\begin{array}{l}\text { Orthostatic hypotension } \\
\text { Palpitations/tachycardia }\end{array}$ \\
\hline Weight changes & $\begin{array}{l}\text { Weight gain } \\
\text { Weight loss }\end{array}$ \\
\hline Sexual symptoms & $\begin{array}{l}\text { Menorrhagia } \\
\text { Amenorrhoea } \\
\text { Galactorrhoea } \\
\text { Gynecomastia } \\
\text { Increased sexual desire } \\
\text { Decreased sexual desire } \\
\text { Erectile dysfunction } \\
\text { Ejaculation disorders } \\
\text { Anorgasmia } \\
\text { Vaginal dryness }\end{array}$ \\
\hline Headache symptoms & $\begin{array}{l}\text { Headache } \\
\text { Tension headache } \\
\text { Migraine }\end{array}$ \\
\hline Dependence symptoms & $\begin{array}{l}\text { Physical dependence } \\
\text { Psychological dependence }\end{array}$ \\
\hline
\end{tabular}

a Movement disorders were measured with a standardised protocol by a trained physiotherapist. 


\subsection{Psychotropic drug use}

Information on medication use was collected through the institutions' pharmacy information systems. Drugs were categorised in somatic medication and psychotropic drugs according to the World Health Organization Anatomic Therapeutic Chemical (ATC) classification system (WHOCC-ATC/DDD index, 2014). Psychotropic drugs included antipsychotics, antidepressants, mood stabilisers, psychostimulants (agents used for ADHD) and benzodiazepines. Use of the medication during the three months before index date was assessed, with the index date being the day on which the physicians filled in the questionnaire. Furthermore, use of $\geq 2$ psychotropic drugs across different drug classes was examined.

\subsection{Quality of life according to the patient and physicians}

Quality of life of patients was assessed by measuring the overall quality of life as reported by the patients and their physician. The patients filled in the Intellectual Disability Quality of Life-16 (IDQOL-16) (de Baaij, Hoekman, Volman, \& Zaad, 2006; Douma, Kersten, Koopman, Schuurman, \& Hoekman, 2001; Hoekman, Douma, Kersten, Schuurman, \& Koopman, 2001) by themselves. They were assisted by a social worker in filling the questionnaire if needed, for instance if they were unable to read the questions. The IDQOL-16 consists of 16 questions about mental aspects, social aspects and aspects about daily living. The score for each question ranged from 1 to 5 , where 1 meant very dissatisfied and 5 meant very satisfied. The patients could answer the questions using 'smileys' ranging from sad faces to happy faces.

The physician filled in the Clinical Global Impression scale (Busner \& Targum, 2007; Guy, 1976b). The clinical impression of the severity of the disease for the patient (CGI-S) at their last contact moment with the patient was filled in on a 7-point scale: 1, normal, not at all ill to 7, extremely ill. The change of the clinical impression since the start of the admission in the institute (CGI-I) was used to measure the patient's improvement relative to the start of the admission. This 7-point scale is rated from 1 , very much improved to 7 , very much worse.

In the UKU side effect rating scale there were two additional questions, which were included here as well (Lingjaerde et al., 1987). These two questions concerned the influence of known adverse events on daily functioning and the consequences for the treatment plan according to the physician. The global assessment of the interference of existing adverse events with the patient's daily functioning was as follows: 0, no adverse events; 1 , mild adverse events that do not interfere with the patient's functioning; 2, adverse events that interfere moderately with the patient's functioning; 3, adverse events that interfere markedly with the patient's functioning. To measure the consequences of this interference for the treatment plan a 4-point scale was use. This scale was rated as follows: 0, no action; 1 , more frequently monitor the patient, but no reduction of dose and/or occasional drug treatment of side effects; 2 , reduction of dose and/or continuous drug, treatment of side effects and 3, discontinuation of drug or change to another preparation.

\subsection{Data analysis}

The baseline characteristics, the medication databases, the adverse events and the consequences of medication use were linked anonymously through record linkage methodology based on an identification number. Data were analysed using IBM SPSS Statistics for Windows, Version 20 (IBM Corp, 2011). If the adverse events were filled in as 'unknown' it was regarded as absent. The overall prevalence of adverse events was assessed, with the total number of patients with these adverse events divided by the total number of included patients. The association with psychotropic medication use was tested using chisquare test for categorical data and an independent sample $t$-test for continuous data. A $p$-value less than 0.05 was considered statistically significant.

Means scores and the SD were calculated for IDQOL scores, CGI-S, CGI-I and influence on daily functioning according to the number of adverse events. The strength of the association between adverse events and IDQOL, adverse events and daily functioning was investigated using linear regression analyses, taking into account the severity of disease (CGI-S) as potential confounder. The consequences as a result of the influence on daily functioning were counted.

\section{Results}

\subsection{Population}

A total of 103 adults with ID and severe challenging behaviour were included in the study. Table 2 describes the population characteristics. Approximately three-quarters of participants were male and the mean age was 31.8 years. Many patients had a diagnosis of alcohol/drug dependence or abuse (39 patients, 37.9\%), a personality disorder (34 patients, 33.0\%), a psychotic disorder (25 patients, 24.3\%) and/or ADHD/conduct disorder (25 patients, 24.3\%). Of the 103 patients, 92 patients (89.3\%) used at least one medication, 80 patients (77.7\%) at least one psychotropic drug and 41 patients (40.0\%) used two or more psychotropic drugs during the three months before index date. 
Table 2

Baseline characteristics and use of medication during the three months before index date $(n=103)$.

\begin{tabular}{|c|c|}
\hline Baseline characteristics & $N$ patient $(\%)$ \\
\hline Total $n=103$ & $103(100.0)$ \\
\hline \multicolumn{2}{|l|}{ Gender } \\
\hline Male & $78(75.7)$ \\
\hline Female & $25(24.3)$ \\
\hline Age (mean, range) & $31.8(15-64)$ \\
\hline$\leq 30$ years & $59(57.3)$ \\
\hline$>30$ years & $44(42.7)$ \\
\hline \multicolumn{2}{|l|}{ Ethnicity $^{\mathrm{a}}$} \\
\hline Dutch parents & $78(75.7)$ \\
\hline Other & $13(12.6)$ \\
\hline \multicolumn{2}{|l|}{ Intellectual disability (IQ) } \\
\hline $50-70$ & $46(44.7)$ \\
\hline $71-84$ & $45(43.7)$ \\
\hline \multicolumn{2}{|l|}{ DSM IV diagnosis ${ }^{\mathrm{b}}$} \\
\hline Psychotic disorder & $25(24.3)$ \\
\hline Mood disorder & $8(7.8)$ \\
\hline Anxiety disorder & $9(8.7)$ \\
\hline Alcohol/drug dependence or abuse & 39 (37.9) \\
\hline ADHD and conduct disorder & $25(24.3)$ \\
\hline Pervasive developmental disorder & $19(18.4)$ \\
\hline Sexual disorder & $9(8.7)$ \\
\hline Personality disorder & $34(33.0)$ \\
\hline \multicolumn{2}{|c|}{ Time between filling in questionnaire and last contact with patient ${ }^{\mathrm{a}}$} \\
\hline$<1$ month ago & $56(54.4)$ \\
\hline Months ago & $34(33.0)$ \\
\hline$>3$ months ago & $10(9.7)$ \\
\hline Use of any medication & $92(89.3)$ \\
\hline Use of any psychotropic drug & $80(77.7)$ \\
\hline Use of antipsychotics & $63(61.2)$ \\
\hline Use of benzodiazepines & $38(36.9)$ \\
\hline Use of antidepressants & $27(26.2)$ \\
\hline Use of stimulants & $7(6.8)$ \\
\hline Use of mood stabilisers & $9(8.7)$ \\
\hline Use of any somatic medication & $78(75.7)$ \\
\hline
\end{tabular}

a Totals do not add up to $100 \%$ due to missing data.

b Patients can have more than 1 DSM IV diagnosis.

\subsection{Prevalence of adverse events in association to psychotropic drug use}

Only sixteen patients (15.5\%) had no adverse events recorded by the physicians (Table 3 ). Almost half of the patients (45.6\%) had three or more adverse events. Psychological symptoms were the most prevalent adverse events (51.5\%) followed by sleeping problems and fatigue (48.5\%), weight changes (35.0\%) and neurological symptoms (34.0\%). Overall, patients using psychotropic drugs had significantly more adverse events than patients not using psychotropic drugs $(p<0.001)$. Psychological symptoms, sleeping problems, fatigue and weight changes were all significantly more often seen in patients using psychotropic drugs $(p<0.05)$.

\subsection{Adverse events in relation to quality of life}

Table 4 shows the relation of adverse events with the quality of life. Patients without any adverse events (mean IDQOL: 4.09) had a better quality of life than patients with 1 or 2 adverse events (3.57) and patients with $\geq 3$ adverse events (3.41) with $p=0.01$, adjusted for severity of disease. Similarly, the mean global rating of the influence on daily functioning was higher ( $p<0.001$, adjusted for severity of disease) in patients with $\geq 3$ adverse events (1.21) compared to patients with 1 or 2 adverse events $(0.24)$ and no adverse event $(0.00)$. The mean global severity of the disease increased with the number of adverse events from 2.50 with no adverse events to 3.77 with $\geq 3$ adverse events. The mean global change showed that the group with no adverse events (2.69) improved more than the groups with 1 or 2 adverse events (2.72) and $\geq 3$ adverse events (2.91). 
Table 3

Prevalence of adverse events in association to psychotropic drug use $(n=103)$.

\begin{tabular}{|c|c|c|c|c|c|}
\hline Adverse events & $\begin{array}{l}\text { All patients } \\
(n=103)\end{array}$ & $\begin{array}{l}\text { No use of } \\
\text { psychotropics } \\
(n=23)\end{array}$ & $\begin{array}{l}\text { Use of } 1 \\
\text { psychotropic } \\
(n=39)\end{array}$ & $\begin{array}{l}\text { Use of } \geq 2 \\
\text { psychotropics } \\
(n=41)\end{array}$ & $p$-Value \\
\hline \multicolumn{6}{|c|}{ Number of adverse events across different subclasses } \\
\hline No adverse events & $16(15.5)$ & $10(43.5 \%)$ & $5(12.8 \%)$ & $1(2.4 \%)$ & \\
\hline 1 or 2 adverse events & $40(38.8)$ & $10(43.5 \%)$ & $15(38.5 \%)$ & $15(36.6 \%)$ & \\
\hline$\geq 3$ adverse events & $47(45.6)$ & $3(13.0 \%)$ & $19(48.7 \%)$ & $25(61.0 \%)$ & $<\mathbf{0 . 0 0}{ }^{*}$ \\
\hline \multicolumn{6}{|l|}{ Adverse events in subclasses } \\
\hline Psychological symptoms & $53(51.5)$ & $6(26.1 \%)$ & $19(48.7 \%)$ & $28(68.3 \%)$ & $<0.01^{*}$ \\
\hline Sleeping problems and fatigue & $50(48.5)$ & $6(26.1 \%)$ & $17(43.6 \%)$ & $27(65.9 \%)$ & $<\mathbf{0 . 0 1}{ }^{*}$ \\
\hline Weight changes & $36(35.0)$ & $2(8.7 \%)$ & $17(43.6 \%)$ & $17(41.5 \%)$ & $0.01^{*}$ \\
\hline Neurological symptoms ${ }^{a}$ & $35(34.0)$ & $3(13.0 \%)$ & $12(30.8 \%)$ & $20(48.8 \%)$ & $0.01^{*}$ \\
\hline Anticholinergic symptoms & $18(17.5)$ & $1(4.3 \%)$ & $8(20.5 \%)$ & $9(22.0 \%)$ & 0.17 \\
\hline Dependence symptoms & $17(16.5)$ & $2(8.7 \%)$ & $7(17.9 \%)$ & $8(19.5 \%)$ & 0.51 \\
\hline Sexual symptoms & $16(15.5)$ & $2(8.7 \%)$ & $9(23.1 \%)$ & $5(12.2 \%)$ & 0.24 \\
\hline Headache symptoms & $9(8.7)$ & $2(8.7 \%)$ & $2(5.1 \%)$ & $5(12.2 \%)$ & 0.54 \\
\hline Cardiovascular symptoms & $7(6.8)$ & $0(0.0 \%)$ & $3(7.7 \%)$ & $4(9.8 \%)$ & 0.32 \\
\hline Gastro-intestinal symptoms & $5(4.9)$ & $1(4.3 \%)$ & $3(7.7 \%)$ & $1(2.4 \%)$ & 0.55 \\
\hline Urogenital symptoms & $5(4.9)$ & $1(4.3 \%)$ & $2(5.1 \%)$ & $2(4.9 \%)$ & 0.99 \\
\hline Sedation mean, SD & $\begin{array}{l}1.44 \text { SD } 0.76 \\
\text { (10 missing) }\end{array}$ & $\begin{array}{l}1.11 \text { SD } 0.32 \\
(5 \text { missing })\end{array}$ & $\begin{array}{l}1.43 \text { SD } 0.85 \\
(4 \text { missing })^{* *}\end{array}$ & $\begin{array}{l}1.60 \text { SD } 0.78 \\
(1 \mathrm{missing})^{* * * *}\end{array}$ & $0.134^{* *} \mathbf{0 . 0 1 3} 3^{* * *}$ \\
\hline
\end{tabular}

SD, standard deviation.

Significant associations are printed in bold ( $p<0.05)$.

Degree of sedation: 1 means no sedation and 5 the highest degree of sedation.

a Neurological symptoms consist of presence of epilepsy or paraesthesia according to the physician or movement disorders measured in a standardised manner.

* p value significant <0.05: adverse events use of psychotropic drugs compared with no psychotropic drug

** p value: sedation use of 1 psychotropic drug compared with no psychotropic drug

*** p value significant $<0.05$ : sedation use of $\geq 2$ psychotropic drugs compared with no psychotropic drug

Table 4

Association between number of adverse events and quality of life.

\begin{tabular}{|c|c|c|c|c|c|}
\hline & \multicolumn{5}{|c|}{ Number of adverse events } \\
\hline & No adverse events & 1 or 2 adverse events & $\geq 3$ adverse events & $p$ & $p^{\mathrm{a}}$ \\
\hline \multicolumn{6}{|l|}{ Patient } \\
\hline IDQOL-score mean (SD) $(n=93)$ & $4.09(0.63)$ & $3.57(0.71)$ & $3.41(0.71)$ & 0.003 & 0.014 \\
\hline \multicolumn{6}{|l|}{ Physicians } \\
\hline $\begin{array}{l}\text { Mean global rating of the influence on daily } \\
\text { functioning (SD) }(n=90)\end{array}$ & $0.00(0.00)$ & $0.24(0.55)$ & $1.21(0.91)$ & 0.000 & 0.000 \\
\hline CGI-S mean (SD) $(n=103)$ & $2.50(1.83)$ & $3.20(1.57)$ & $3.77(2.05)$ & 0.015 & \\
\hline CGI-I mean (SD) $(n=103)$ & $2.69(0.70)$ & $2.72(0.82)$ & $2.91(1.38)$ & 0.384 & \\
\hline
\end{tabular}

SD, standard deviation, IDQOL, intellectual disability quality of life, CGI-S, clinical global impression-severity, CGI-I, clinical global impression-change Significant associations are printed in bold $(p<0.05)$.

a Adjusted for severity of disease (CGI-S).

In 23 (25.5\%) out of 90 participants the physician indicated that they would change the treatment plan of the patient as a result of the perceived effect on the quality of life. In five patients they would discontinue the drug or change to another drug. In eight patients they would decrease the dose of the drug, in ten patients they would monitor the patient more frequently.

\section{Discussion}

The present study shows that almost half of all participants had $\geq 3$ adverse events (45.6\%) across different subclasses and in the remaining part many persons also had one or two adverse events (38.8\%). Psychological symptoms, sleeping problems and fatigue, weight changes and neurological symptoms were the most prevalent adverse events. Using any or multiple psychotropic drugs significantly increased the prevalence of adverse events, in particular if they used $\geq 2$ psychotropic drugs. The presence of adverse events was negatively associated with the quality of life according to the patient. There was a clinical significant association of adverse events with the influence on daily functioning according to the physician. After adjustment for the severity of disease these associations remained significant. However, in most patients the physicians did not intend to take any action regarding the drug treatment plan. 
In a previous study conducted by Friedlander et al., the prevalence of neuroleptic induced movement disorders (NIMDs) in 54 adolescents and young adults with developmental disabilities was examined. They found that $17 \%$ of the patients on risperidone had NIMDs and $21 \%$ of the patients on olanzapine (Friedlander et al., 2001). Our results show that in all patients $34.0 \%$ had neurological symptoms and in patients on psychotropic drugs this was $40.0 \%$. Thus, the prevalence in our study was considerably higher. The study population of Friedlander et al. consisted of adolescents and young adults and our population consisted of adults who probably also had a longer history of psychotropic drug use. It has been demonstrated that the prevalence of movement disorders increases with longer duration of psychotropic drug use (de Kuijper et al., 2013). Besides, Friedlander et al. included only patients with risperidone and olanzapine, compared to all psychotropic drugs in our study. Mahan et al. studied the association between using a larger number of psychotropic drugs from different classes and the presence of side effects in 80 adults with ID (Mahan et al., 2010). A comparison was made between those taking zero, one and two psychotropic medications across different medication classes. It was shown that adults with ID taking any psychotropic drug present with significantly more and more severe side effects than adults with ID not taking psychotropic drugs. There was no statistically significant difference between adults taking one or two classes of psychotropic drugs, although for some side effect subscales the mean scores were higher for the group taking two psychotropic drugs than the group taking one psychotropic. In the current study the association between taking psychotropic drugs and the prevalence of adverse events was also shown. The prevalence of the different adverse events was higher in the group taking two or more psychotropic drugs than in the group taking one psychotropic drug. Patients with psychotropic drug use had significantly more adverse events than patients without psychotropic drugs. In a cohort study of children and adolescents without ID the same relation between increasing numbers of medication used and number and severity of side effects was found (Hilt et al., 2014).

In this study the prevalence of sexual symptoms increased with the number of psychotropic drugs used. Compared to a study of Roke et al. (2012) this prevalence is low. However, often physicians filled in that these symptoms were unknown, which might indicate underreporting. There is still a taboo on asking for sexual symptoms, especially in this population.

As far as we know this is the first study in people with ID to measure the association between adverse events and quality of life. Quality of life is an important aspect of treatment outcome and should be included in pharmacological studies (Townsend-White, Pham, \& Vassos, 2012; Zarcone et al., 2008). In a study in elderly patients treated with haloperidol the presence of antipsychotic induced parkinsonism was negatively associated with the quality of life (Schouten et al., 2012). According to Hemmings et al, when treating patients with ID with psychotropic drug use, not only symptom reduction but also improving quality of life of the patient with ID and their caregivers are main goals in the treatment (Hemmings et al., 2013).

From the benefit-harm evidence in literature or guidelines, there are no justifications for the high prevalence of psychotropic drug use (Scheifes et al., 2011; de Kuijper et al., 2010). Possible explanations could include: no other treatment options available, looking for a quick fix, fear to stop, pressure by family and care-takers (Deb et al., 2009). A consequence of high rates of psychotropic drug use with extensive (often long term) off-label prescribing is a high risk of adverse events. More insight in adverse events and the impact on the quality of life should stimulate change in prescribing practices. To improve the quality of prescribing with more attention for the indications, the adverse events and quality of life, a structured medication review can be an effective intervention. Such an intervention should not only take into account the pharmacological actions of the drug but also include the management of the beliefs and attitude of caregivers and relatives (Scheifes, Egberts, Stolker, Nijman, \& Heerdink, 2015).

\subsection{Strengths and limitations}

A strength of this study is the combination of measurement of the prevalence of adverse events and quality of life in adults with ID, a population that is often difficult to recruit and engage in research. Another strength of this study is that accurate pharmacy data were available and that demographic data and information about hospitalisation in the centres could be extracted from basic registration lists that also included DSM-IV diagnoses and level of intellectual functioning.

The quality of life of these participants was measured with a standardised questionnaire of 16 questions that could be filled in by the patients themselves or with help from a social worker. The questions were easy to understand for these adults and they could answer them by using smileys. A disadvantage of the questionnaire about quality of life is that people with ID are prone to give answers that are socially desirable or that they do not recognise their limitations in daily functioning, which may lead to an overestimation of their quality of life.

Not all patients had a diagnosis in accordance with the DSM-IV; sometimes only a descriptive diagnosis was available. The medication data were collected from pharmacy databases; however, there was no information about the reasons for prescription of the medications. Furthermore, this study was performed in inpatient adults with ID and challenging behaviour, so these results cannot be generalised to the outpatient population.

The questionnaires also showed that it can be difficult for physicians to specify if a symptom is drug related or not. The information whether an adverse event was drug related or not, was hardly filled in by the physician and could not be analysed. Especially in persons with ID it appears difficult to discriminate if symptoms belong to the underlying disorder, the medication given or the ID (Valdovinos et al., 2005; Zarcone et al., 2008). Tools should be developed to perform causality assessment in patients with ID. 


\section{Conclusion}

A large majority (84.4\%) of 103 adults with ID and challenging behaviour had at least one adverse event across different subclasses. Using any or multiple psychotropic drugs strongly increased the prevalence of adverse events. More attention is needed for these adverse events and their negative influence on the quality of life of these patients, taking into account the lack of evidence of effectiveness of psychotropic drugs for challenging behaviour.According to the patients themselves:

- IDQOL score: 1 means very dissatisfied and 5 means very satisfied.

According to the physician:

- Global rating of the influence on daily functioning: 0 , no side effects; 1 , mild side effects that do not interfere with the patient's performance; 2 , side effects that interfere moderately with the patient's performance; 3 , side effects that interfere markedly with the patient's performance.

- Mean global severity of the disease (CGI-S): 1, normal, not at all ill; 2, borderline ill; 3, mildly ill; 4, moderately ill; 5 , markedly ill; 6 , severely ill or 7 , extremely ill.

- Mean global change since admission to the institute (CGI-I): 1, very much improved; 2, much improved; 3, minimally improved; 4 , no change; 5 , minimally worse; 6 , much worse or 7 , very much worse.

\section{Acknowledgements}

This research was funded by the Netherlands Organization for Health Research and Development (ZonMw57000004). The authors gratefully thank the department "Wier" of Altrecht Aventurijn, Ipse de Bruggen and Trajectum of knowledge centre "De Borg" for their participation, our physiotherapist J. Polak for the measurement of movement disorders, and our research assistants $M$. van Woudenberg and T. van den Brink for their assistance in collecting the data.

\section{References}

Advokat, C. D., Mayville, E. A., \& Matson, J. L. (2000). Side effect profiles of atypical antipsychotics, typical antipsychotics, or no psychotropic medications in persons with mental retardation. Research in Developmental Disabilities, 21, 75-84.

Aman, M. G., De Smedt, G., Derivan, A., Lyons, B., \& Findling, R. L. Risperidone, Disruptive Behavior Study Group. (2002). Double-blind, placebo-controlled study of risperidone for the treatment of disruptive behaviors in children with subaverage intelligence. The American Journal of Psychiatry, 159, 13371346.

American Psychiatric Association. (2000). Diagnostic and statistical manual of mental disorders (4th ed.). Washington, DC.

Barnes, T. R. E. (1989). A rating scale for drug-induced akathisia. British Journal of Psychiatry, 154, 672-676.

Bertelli, M., Micaela, P. M., Rossi, M., Lassi, S., Bianco, A., \& Colangelo, J. (2013). Quality of life in pharmacological intervention on autism spectrum disorders. Advances in Mental Health and Intellectual Disabilities, 7, 40-48.

Brylewski, J., \& Duggan, L. (1999). Antipsychotic medication for challenging behaviour in people with intellectual disability: A systematic review of randomized controlled trials. Journal of Intellectual Disability Research, 43, 360-371.

Busner, J., \& Targum, S. D. (2007). The clinical global impressions scale: Applying a research tool in clinical practice. Psychiatry, 4, 28-37.

Charlot, L., Abend, S., Ravin, P., Mastis, K., Hunt, A., \& Deutsch, C. (2011). Non-psychiatric health problems among psychiatric inpatients with intellectual disabilities. Journal of Intellectual Disability Research, 55, 199-209.

Cooper, S. A., Smiley, E., Allan, L. M., Jackson, A., Finlayson, J., Mantry, D., et al. (2009). Adults with intellectual disabilities: Prevalence, incidence and remission of self-injurious behaviour, and related factors. Journal of Intellectual Disability Research, 53, $200-216$.

Cooper, S. A., Smiley, E., Morrison, J., Williamson, A., \& Allan, L. (2007). Mental ill-health in adults with intellectual disabilities: Prevalence and associated factors. British Journal of Psychiatry, 190, 27-35.

Crocker, A. G., Mercier, C., Lachapelle, Y., Brunet, A., Morin, D., \& Roy, M. E. (2006). Prevalence and types of aggressive behaviour among adults with intellectual disabilities. Journal of Intellectual Disability Research, 50, 652-661.

de Baaij, E. J., Hoekman, J., Volman, M. J. M., \& Zaad, C. (2006). Kwaliteit van bestaan bij mensen met een complex meervoudige beperking- een bepaling met de IDQOL-16 [quality of life of people with complex multiple disabilities- a measurement with the IDQOL-16]. Nederlands Tijdschrift voor de Zorg aan verstandelijk gehandicapten, 1, 13-26.

de Kuijper, G., Hoekstra, P., Visser, F., Scholte, F. A., Penning, C., \& Evenhuis, H. (2010). Use of antipsychotic drugs in individuals with intellectual disability (ID) in the Netherlands: Prevalence and reasons for prescription. Journal of Intellectual Disability Research, 54, 659-667.

de Kuijper, G., Mulder, H., Evenhuis, H., Scholte, F., Visser, F., \& Hoekstra, P. J. (2013). Determinants of physical health parameters in individuals with intellectual disability who use long-term antipsychotics. Research in Developmental Disabilities, 34, $2799-2809$.

Deb, S., Thomas, M., \& Bright, C. (2001). Mental disorder in adults with intellectual disability. 2: The rate of behaviour disorders among a community-based population aged between 16 and 64 years. Journal of Intellectual Disability Research, 45, 506-514.

Deb, S., \& Unwin, G. L. (2007). Psychotropic medication for behaviour problems in people with intellectual disability: A review of the current literature. Current Opinion in Psychiatry, 20, 461-466.

Deb, S., Kwok, H., Bertelli, M., Salvador-Carulla, L., Bradley, E., \& Torr, J. (2009). International guide to prescribing psychotropic medication for the management of problem behaviours in adults with intellectual disabilities. World Psychiatry, 8(3), 181-186.

Dosen, A., \& Day, K. (Eds.). (2001). Treating mental illness and behaviour disorders in children and adults with mental retardation. Washington DC: American Psychiatric Press, Inc.

Douma, J. C. H., Kersten, M. C. O., Koopman, H. M., Schuurman, M. I. M., \& Hoekman, J. (2001). Het 'meten' van kwaliteit van bestaan van mensen met een verstandelijke handicap- een overzicht van de nederlandse instrumenten ['measuring' the quality of life of people with intellectual disabilities-An overview of the dutch instruments]. Nederlands Tijdschrift voor de Zorg aan verstandelijk gehandicapten, 27, $17-36$.

Fodstad, J. C., Bamburg, J. W., Matson, J. L., Mahan, S., Hess, J. A., Neal, D., et al. (2010). Tardive dyskinesia and intellectual disability: An examination of demographics and topography in adults with dual diagnosis and atypical antipsychotic use. Research in Developmental Disabilities, $31,750-759$.

Friedlander, R., Lazar, S., \& Klancnik, J. (2001). Atypical antipsychotic use in treating adolescents and young adults with developmental disabilities. Canadian Journal of Psychiatry, 46, 741-745.

Frighi, V., Stephenson, M. T., Morovat, A., Jolley, I. E., Trivella, M., Dudley, C. A., et al. (2011). Safety of antipsychotics in people with intellectual disability. The British Journal of Psychiatry, 199, 289-295. 
Gagiano, C., Read, S., Thorpe, L., Eerdekens, M., \& Van Hove, I. (2005). Short- and long-term efficacy and safety of risperidone in adults with disruptive behavior disorders. Psychopharmacology, 179, 629-636.

Guy, W. (1976a). Abnormal involuntary movement scale. ECDEU assessment manual for psychopharmacology. Rockville (Maryland): National Institute of Mental Health (revised).

Guy, W. (1976b). Clinical global impressions. ECDEU assessment manual for psychopharmacology. Rockville (Maryland): National Institute of Mental Health (revised)

Hemmings, C., Deb, S., Chaplin, E., Hardy, S., \& Mukherjee, R. (2013). Review of research for people with ID and mental health problems: A view from the united kingdom. Journal of Mental Health Research in Intellectual Disabilities, 6, 127-158.

Hilt, R. J., Chaudhari, M., Bell, J. F., Wolf, C., Koprowicz, K., \& King, B. H. (2014). Side effects from use of one or more psychiatric medications in a population-based sample of children and adolescents. Journal of Child and. Adolescent Psychopharmacology, 24, 1-7.

Hoekman, J., Douma, J. C. H., Kersten, M. C. O., Schuurman, M. I. M., \& Koopman, H. M. (2001). IDQOL- intellectual disability quality of life. De ontwikkeling van een instrument ter bepaling van de 'kwaliteit van bestaan' van mensen met een verstandelijke handicap [IDQOL-Intellectual disability quality of life. The development of an instrument for determining the 'quality of life' of people with intellectual disabilities]. Nederlands Tijdschrift voor de Zorg aan verstandelijk gehandicapten, 4, 207-224.

Holden, B., \& Gitlesen, J. P. (2004). Psychotropic medication in adults with mental retardation: Prevalence, and prescription practices. Research in Developmental Disabilities, 25, 509-521.

IBM Corp. (2011). Released IBM SPSS Statistics for Windows, Version 20.0.. Armonk, NY: IBM Corp.

Lingjaerde, O., Ahlfors, U. G., Bech, P., Dencker, S. J., \& Elgen, K. (1987). The UKU side effect rating scale. A new comprehensive rating scale for psychotropic drugs and a cross-sectional study of side effects in neuroleptic-treated patients. Acta Psychiatrica Scandinavica Supplementum, 334, 1-100.

Mahan, S., Holloway, J., Bamburg, J. W., Hess, J. A., Fodstad, J. C., \& Matson, J. L. (2010). An examination of psychotropic medication side effects: Does taking a greater number of psychotropic medications from different classes affect presentation of side effects in adults with ID? Research in Developmental Disabilities, 31, 1561-1569.

Martínez-Martín, P., Gil-Nagel, A., Gracia, L. M., Gómez, J. B., Martínez-Sarriés, J., \& Bermejo, F. (1994). Unified Parkinson’s disease rating scale characteristics and structure. Movement Disorders, 9, 76-83.

Matson, J. L., \& Mahan, S. (2010). Antipsychotic drug side effects for persons with intellectual disability. Research in Developmental Disabilities, 31, 1570-1576.

Matson, J. L., \& Neal, D. (2009). Psychotropic medication use for challenging behaviors in persons with intellectual disabilities: An overview. Research in Developmental Disabilities, 30, 572-586.

McKee, J. R., Bodfish, J. W., Mahorney, S. L., Heeth, W. L., \& Ball, M. P. (2005). Metabolic effects associated with atypical antipsychotic treatment in the developmentally disabled. Journal of Clinical Psychiatry, 66, 1161-1168.

Roke, Y., Buitelaar, J. K., Boot, A. M., Tenback, D., \& Van Harten, P. N. (2012). Risk of hyperprolactinemia and sexual side effects in males 10-20 years old diagnosed with autism spectrum disorders or disruptive behavior disorder and treated with risperidone. Journal of Child and Adolescent Psychopharmacology, 22, 432-439.

Scheifes, A., Stolker, J. J., Egberts, A. C. G., Nijman, H. L. I., \& Heerdink, E. R. (2011). Representation of people with intellectual disabilities in randomised controlled trials on antipsychotic treatment for behavioural problems. Journal of Intellectual Disability Research, 55, 650-664.

Scheifes, A., Egberts, T. C. G., Stolker, J. J., Nijman, H. L. I., \& Heerdink, E. R. (2015). Structured medication review to improve pharmacotherapy in people with intellectual disability and behavioural problems. Journal of Applied Research in Intellectual Disabilities. http://dx.doi.org/10.1111/jar.12183 (April 16, Epub ahead of print)

Schouten, H. J., Knol, W., Egberts, T. C. G., Schobben, A. F. A. M., Jansen, P. A. F., \& van Marum, R. J. (2012). Quality of life of elderly patients with antipsychotic-induced parkinsonism: A cross-sectional study. Journal of the American Medical Directors Association, 13. 82.e1-82.e5.

Singh, N. N., Ellis, C. R., \& Wechsler, H. (1997). Psychopharmacoepidemiology of mental retardation: 1966 to 1995. Journal of Child and Adolescent Psychopharmacology, 7, 255-266.

Snyder, R., Turgay, A., Aman, M., Binder, C., Fisman, S., Carroll, A., et al. (2002). Effects of risperidone on conduct and disruptive behavior disorders in children with subaverage IQs. Journal of the American Academy of Child and Adolescent Psychiatry, 41, 1026-1036.

Townsend-White, C., Pham, A. N. T., \& Vassos, M. V. (2012). Review: A systematic review of quality of life measures for people with intellectual disabilities and challenging behaviours. Journal of Intellectual Disability Research, 56, 270-284.

Tsiouris, J. A. (2010). Pharmacotherapy for aggressive behaviours in persons with intellectual disabilities: Treatment or mistreatment? Journal of Intellectual Disability Research, 54, 1-16.

Tsiouris, J. A., Kim, S. Y., Brown, W. T., Pettinger, J., \& Cohen, I. L. (2013). Prevalence of psychotropic drug use in adults with intellectual disability: Positive and negative findings from a large scale study. Journal of Autism and Developmental Disorders, 43, 719-731.

Tyrer, P., Oliver-Africano, P. C., Ahmed, Z., Bouras, N., Cooray, S., Deb, S., et al. (2008). Risperidone, haloperidol, and placebo in the treatment of aggressive challenging behaviour in patients with intellectual disability: A randomised controlled trial. Lancet, 371, 57-63.

Valdovinos, M. G., Caruso, M., Roberts, C., Kim, G., \& Kennedy, C. H. (2005). Medical and behavioral symptoms as potential medication side effects in adult with developmental disabilities. American Journal on Mental Retardation, 110, 164-170.

van Harten, P. N., Matroos, G. E., Hoek, H. W., \& Kahn, R. S. (1996). The prevalence of tardive dystonia, tardive dyskinesia, parkinsonism and akathisia the curaçao extrapyramidal syndromes study: I. Schizophrenia Research, 19, 195-203.

WHOCC-ATC/DDD index, 2014. Available at: 〈http://www.whocc.no/atc_ddd_index/〉 (accessed 20.06.14).

Zarcone, J. R., Napolitano, D., \& Valdovinos, M. (2008). Measurement of problem behaviour during medication evaluations. Journal of Intellectual Disability Research, 52, 1015-1028. 